J. M. FRANKE, B. K. RALISKI, S. C. BOGGESS, D. V. NATESAN, E. T. KORETSKY, P. ZHANG, R. U. KULKARNI, P. E. DEAL, E. W. MILLER* (UNIVERSITY OF CALIFORNIA, BERKELEY, USA)

BODIPY Fluorophores for Membrane Potential Imaging

J. Am. Chem. Soc. 2019, 141, 12824-12831.

\section{Water-Soluble BODIPY Dyes for Voltage Imaging}

Synthesis of water-soluble BODIPY VF dyes:

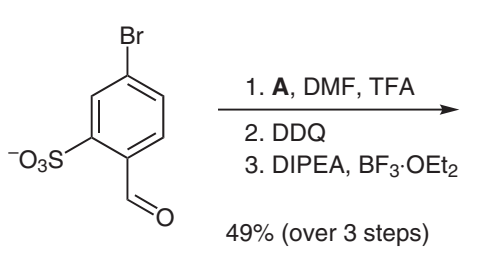<smiles></smiles>

Heck reaction B, $\mathrm{Pd}(\mathrm{OAc})_{2}$ $(\mathrm{O}-\mathrm{tol})_{3} \mathrm{P}$ $92 \%$ yield $\left(\mathrm{R}^{1}=\mathrm{H}\right)$ $25 \%$ yield $\left(R^{1}=\mathrm{OMe}\right)$<smiles>CCc1c(C)c[nH]c1C</smiles>

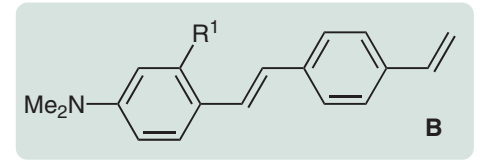<smiles>CNc1ccc(/C=C/c2ccc(I)cc2)c(Br)c1</smiles>

BODIPY VF series:<smiles></smiles>

$$
\begin{aligned}
& \mathrm{R}^{1}= \mathrm{H} \\
& \mathrm{Me} \\
& \mathrm{OMe} \\
& \mathrm{R}^{2}= \mathrm{Me} \\
& \mathrm{Et} \\
& \mathrm{R}^{3}= \mathrm{H} \\
& \mathrm{Et} \\
& \mathrm{CO}_{2}^{-} \\
& \mathrm{CONHR} \\
& \mathrm{CN}
\end{aligned}
$$

Significance: Previously, water solubility of BODIPY dyes was achieved through direct functionalization of the BODIPY fluorophore. Miller and coworkers report an elegant and versatile solution that does not significantly alter the dye electronics through introduction of a sulfonate on the meso-aromatic ring. These fluorophores are used to generate a series of new VoltageFluor (VF) dyes that enable the recording of action potential dynamics in neurons and cardiomyocytes.
Comment: The TFA-catalyzed condensation of aldehydes with pyrroles in the synthesis of BODIPY dyes is commonly performed in $\mathrm{CH}_{2} \mathrm{Cl}_{2}$ and often reported to be low-yielding. Here, the authors optimized this reaction with their sulfonated aldehyde, which was found to be insoluble in $\mathrm{CH}_{2} \mathrm{Cl}_{2}$ and toluene. Comparably good yields were obtained in DMF (e.g. 49\% over three steps, see above). Therefore, the reported strategy for water-soluble BODIPY synthesis could be very useful for the wider community.

\section{Category}

Chemistry in Medicine and Biology

Key words

voltage dyes

fluorophores

BODIPY

\section{Synifact Month}

